\title{
INHIBITOR OF ADENOSINE 3':5'-MONOPHOSPHATE-DEPENDENT PROTEIN KINASE BLOCKS PRESYNAPTIC FACILITATION IN APLYSIA ${ }^{1}$
}

\author{
V. F. CASTELLUCCI, ${ }^{*}, 2$ A. NAIRN, $\ddagger$ P. GREENGARD, $\neq J$. H. SCHWARTZ, ${ }^{*}$ AND E. R. KANDEL* \\ * Departments of Psychiatry, Neurology, and Physiology, Center for Neurobiology and Behavior, College of Physicians and \\ Surgeons, Columbia University and New York State Psychiatric Institute, New York, New York 10032 and $\ddagger$ Depurtment of \\ Pharmacology, Yale University School of Medicine, New Haven, Connecticut 06510
}

Received June 21, 1982; Revised August 30, 1982; Accepted September 3, 1982

\begin{abstract}
Sensitization of the gill withdrawal reflex results from presynaptic facilitation at the excitatory synapses made by sensory neurons on gill motor neurons. Facilitation is accompanied by an increase in the duration of the action potential in sensory cells because of the depression of a $\mathrm{K}^{+}$current. This results in an increased influx of $\mathrm{Ca}^{2+}$ and a greater release of transmitter from sensory neurons. There is evidence that serotonin is the facilitating transmitter and that the depression of the $\mathrm{K}^{+}$ current by serotonin is mediated by cAMP-dependent protein phosphorylation.

To test further the role of the cAMP-dependent protein kinase and of protein phosphorylation in sensitization, we have attempted to prevent or reverse the development of the electrophysiological correlates that accompany sensitization. We have pressure-injected sensory neurons with a specific and a stable protein inhibitor of the cAMP-dependent protein kinase both before and after the application of serotonin or the activation of the facilitator neurons. The increase in spike broadening that accompanies facilitation was prevented or diminished by injection of the inhibitor.

Moreover, injection of the inhibitor could reverse fully the developed spike broadening produced by prior application of serotonin. These observations strengthen the evidence for the involvement of protein phosphorylation in presynaptic facilitation. Phosphorylation of the substrate protein evidently is quite labile and does not persist after the kinase is inhibited. Thus, the time course of short term sensitization appears to be determined by an active kinase. We think that it is likely that the mechanism for maintaining the kinase in an active form resides in the slow decay of the cAMP produced by the action of serotonin or the facilitator neurons on the sensory cells.
\end{abstract}

Protein phosphorylation has been implicated in many physiological processes in various cellular systems, including neurons (Rosen and Krebs, 1981). Moreover, it has been postulated that protein kinase mediates most, if not all, of the effects of cAMP in eukaryotic cells (Greengard, 1978; Rall, 1979; Walsh et al., 1968). In the nervous system, it has been difficult to relate protein phosphorylation to a specific role in neuronal function, but phosphorylation has been shown to cause the presynaptic facilitation that underlies short term sensitization of the gill withdrawal reflex in Aplysia.

\footnotetext{
'This work was supported by Research Scientist Award MH18558 15, a McKnight Foundation Grant, and National Institute of Neurological and Communicative Disorders and Stroke Grant NS12744. We wish to thank Louise Katz and Kathrin Hilten for the illustrations.

${ }^{2}$ To whom correspondence should be addressed at the Center for Neurobiology and Behavior, The New York State Psychiatric Institute, 722 West 168th Street, New York, NY 10032.
}

Based on a series of biophysical and pharmacological studies, Klein and Kandel (1980) have proposed a detailed molecular model for presynaptic facilitation (Fig. 1). According to this model, serotonin released by facilitating neurons (the L29 cells) activates a serotonin-sensitive adenylate cyclase in the sensory neurons of the gill withdrawal reflex, which leads to an increase in cAMP within the terminals. cAMP activates a protein kinase that phosphorylates a $\mathrm{K}^{+}$channel protein (or a protein that is associated with it). This $\mathrm{K}^{+}$channel normally contributes importantly to the repolarization of the action potential in the sensory neuron. Phosphorylation of this protein leads to the closure of the $\mathrm{K}^{+}$channel, thereby slowing the repolarization of the membrane and prolonging the duration of the action potential. This in turn allows more $\mathrm{Ca}^{2+}$ to flow into the sensory neuron terminals and more transmitter to be released.

There is now substantial experimental support for many aspects of this model; several lines of evidence 
indicate that the presynaptic facilitator neurons use serotonin (or a closely related substance) as their transmitter. These facilitator cells have a high affinity uptake system for serotonin (Hawkins et al., 1981a). Moreover, serotonin, but not a variety of other transmitters, simulates both the enhancement of transmitter release and the depression of the $\mathrm{K}^{+}$channel (Tomosky-Sykes, 1978; Brunelli et al., 1976). These actions are blocked by cinanserin, a serotonin-blocking agent (Brunelli et al., 1976). Finally, as shown in the companion paper (Bernier et al., 1982), serotonin selectively increases the synthesis of cAMP in sensory neurons.

To show that protein phosphorylation is involved in presynaptic facilitation, we previously injected the purified catalytic subunit of bovine cAMP-dependent protein kinase into the cell bodies of individual sensory neurons (Castellucci et al., 1980). Intracellular injection of the kinase simulated the synaptic facilitation observed during behavioral sensitization, causing broadening of the action potential and increasing transmitter release. To explore the role of cAMP-dependent protein phosphorylation in synaptic facilitation further, we have now carried out complementary experiments in which we examine the consequences of injecting a specific inhibitor of the protein kinase on synaptic facilitation. This inhibitor reacts specificially with the catalytic subunit of the cAMP-dependent protein kinase but not with other known types of protein kinases (Krebs and Beavo, 1979). Since injection of protein kinase decreases the $\mathrm{K}^{+}$current and increases the duration of the action potential and transmitter release, we predicted that injection of an inhibitor of the protein kinase would prevent the increase in spike duration and transmitter release that accompany behavioral sensitization. We have confirmed these predictions.

Injection of the kinase inhibitor also has allowed us to answer two other questions: (1) what is the biochemical step responsible for the persistence of the memory for short term sensitization? (2) Does synaptic depression, which underlies habituation, also depend on a cAMPdependent phosphorylation? Our results indicate that the persistence of the memory for this reflex lies in a step in the cAMP cascade that occurs before the phosphorylation of the substrate protein, either in a persistent elevation in the activity of adenylate cyclase or in a depression of phosphodiesterase activity. We also have found that habituation is independent of a cAMP-dependent phosphorylation.

Some of these results have been presented previously in preliminary form (Castellucci et al., 1981).

\section{Materials and Methods}

Abdominal ganglia were removed from Aplysia californica weighing 75 to $200 \mathrm{gm}$ that were kept in marine aquaria at $15^{\circ} \mathrm{C}$ and fed on alternate days. The animals were anesthetized by injection into the hemocoel of isotonic $\mathrm{MgCl}_{2}$ (50\% of body weight) which blocks chemical synaptic transmission centrally and peripherally. To minimize stimulation of the ganglion during the surgical procedure, which involved cutting peripheral nerves and connectives, ganglia were isolated and maintained in sea water containing high $\mathrm{Mg}^{2+}(220 \mathrm{~mm})$ and low $\mathrm{Ca}^{2+}$ (1 mM) concentrations until the connective tissue sheath was removed from the left ventral side to expose the LE cluster of sensory cells.

Electrophysiological experiments. Cells from the LE cluster were identified by position, antidromic activation upon stimulation of the siphon nerve, and absence of synaptic or spike activity except when stimulated (Byrne et al., 1974). To assess changes in the $\mathrm{Ca}^{2+}$ current in sensory neurons, we bathed the ganglia in the presence of 0.05 or $0.1 \mathrm{M}$ tetraethylammonium chloride (TEA; Eastman, Rochester, NY) in an artificial sea water supplemented with amino acids and vitamins (Eisenstadt et al., 1973). In the experiments in which postsynaptic potentials evoked by sensory cells were monitored, the concentrations of $\mathrm{Ca}^{2+}$ and $\mathrm{Mg}^{2+}$ were increased in order to reduce background spontaneous synaptic activity in the follower cells. The composition of this sea water was $375 \mathrm{~mm} \mathrm{NaCl}, 10 \mathrm{~mm} \mathrm{KCl}, 25 \mathrm{~mm} \mathrm{CaCl}_{2}, 2.5 \mathrm{~mm} \mathrm{NaHCO}_{3}$, $100 \mathrm{~mm} \mathrm{MgCl}, 10 \mathrm{~mm}$ Tris-HCl (pH 7.6).

TEA greatly increases the duration of the spike in sensory cells by partially depressing repolarizing $\mathrm{K}^{+}$currents. In these cells, the duration of the action potential is a good index of the $\mathrm{Ca}^{2+}$ current (Klein and Kandel, 1978). The time required for the action potential to fall to half its maximal amplitude was used as a quantitative measure of the duration of the action potential. To minimize spontaneous contractions of the sheath that appear in TEA, the ganglion was treated with $0.5 \%$ glutaraldehyde for $40 \mathrm{sec}$ before the application of the TEA.

Electrophysiological experiments were performed at room temperature (about $21^{\circ} \mathrm{C}$ ). Sensory cells were impaled with double barreled glass micropipettes, one barrel for injection and the other for stimulating and recording. We used short, 5-msec intracellular pulses to avoid distortion of the action potential by bridge circuit artifacts. Single or double barreled electrodes were used to record the activities of the follower cells.

Preparation of the kinase inhibitor. The protein kinase inhibitor was purified from rabbit skeletal muscle by a modification of the method of McPherson et al. (1979). Briefly, after the trichloroacetic acid precipitation step used by these authors, additional ion exchange chromatography using DEAE-cellulose (Whatman DE 52) was performed at $\mathrm{pH} 8.5$ (Nimmo and Cohen, 1978). Further, gel filtration on a Sephadex G-100 column (2.5 $\times 90 \mathrm{~cm}$ ) in $50 \mathrm{~mm}$ ammonium bicarbonate replaced the preparative electrophoresis step used by $\mathrm{McPherson}$ et al. (1979), after which the fractions containing the protein kinase inhibitor were combined and lyophilized. The final lyophilized protein was dissolved and dialyzed at a concentration of $0.34 \mathrm{mg} / \mathrm{ml}$ in $5 \mathrm{~mm}$ imidazole and $1 \mathrm{mM}$ EDTA (pH 6.8) (vehicle buffer). The inhibitor was kept frozen in small samples that were thawed just before injection. The solution to be injected was drawn into the tip of the pipette as described by Castellucci et al. (1980).

Serotonin creatinine sulfate (Sigma Chemical Co., St. Louis, MO) was added to the $5-\mathrm{ml}$ bath containing the abdominal ganglion at final concentrations of $5 \times 10^{-8}$ to $10^{-4} \mathrm{M}$ which were achieved within $30 \mathrm{sec}$. To activate the facilitator interneurons, the left connective was stim- 
ulated electrically using external bipolar silver chloride electrodes (Hawkins et al., 1981b). Typical stimulating parameters were 6 - to $8-\mathrm{Hz}, 10-\mathrm{sec}$ train, 5 -msec duration pulses at 50 to $100 \mathrm{~V}$.

\section{Results}

Serotonin causes parallel increases in spike duration in two different sensory cells. The events proposed to underlie presynaptic facilitation are illustrated in Figure 1. The facilitating neurons are thought to release serotonin which acts on a serotonin-sensitive adenylate cyclase to increase cAMP and activate a cAMP-dependent protein kinase. The action of the kinase decreases a $\mathrm{K}^{+}$ conductance and increases the duration of the action potential in sensory cells. The broadening of the action potential results in an increased influx of $\mathrm{Ca}^{2+}$ and the release of more transmitter. Although detectable in the absence of TEA, the increase in spike duration is unmasked by blocking the other $\mathrm{K}^{+}$channels, the delayed and the early, with TEA (see "Materials and Methods").

Klein and Kandel (1980) used a final concentration of $10^{-4} \mathrm{M}$ serotonin in their studies because it produced a large increase in the duration of the action potential. To test the ability of the kinase inhibitor to block the action of serotonin, we wanted to use a submaximal concentration and therefore determined the dose response for spike broadening. We found that a concentration of $5 \times 10^{-8}$ $\mathrm{M}$ produced a very modest effect and $1 \times 10^{-6} \mathrm{M}$ produced a robust effect that still was submaximal (Table I). We therefore used a concentration of $1 \times 10^{-6} \mathrm{M}$ in all of the experiments to follow. If the application of serotonin was repeated within a 30 -min period, the response to the second application was reduced substantially. At $10^{-6} \mathbf{M}$, the effect of the second application was reduced from 337 $\pm 29 \%$ to $130 \pm 25 \%(N=3)$.

The magnitude by which spikes broaden varies in sensory cells from different ganglia, but there was much less variation between cells from the same ganglion. To reduce the variability in each experiment, we always compared two sensory neurons from the same ganglion. To establish the reliability of the paired comparison, wc carried out a series of experiments and found that serotonin consistently produced similar effects in both cells. The onset, peak amplitude, and duration of the spike increase were always parallel (Fig. 2A). Parallel increases also were noted in both cells when the connectives were stimulated so as to activate the facilitator neurons (Fig. $2 B)$.

Protein kinase inhibitor blocks the spike broadening produced by serotonin. We next carried out experiments in which serotonin was added to the bath to produce spike broadening after one neuron, the experimental neuron, was injected with the kinase inhibitor and the other served as a control. In each of seven paired comparisons, the increase in spike broadening produced by serotonin in the experimental cell was diminished consid-

TABLE I

Serotonin dose response for spike broadening

\begin{tabular}{ccc}
\hline $\begin{array}{c}\text { Concentration of Sero- } \\
\text { tonin }\end{array}$ & $\begin{array}{c}\text { Number of Experi- } \\
\text { ments }\end{array}$ & $\begin{array}{c}\text { Maximum Increase above } \\
\text { Control Spike Duration }\end{array}$ \\
\hline$M$ & & $\%$ \\
$5 \times 10^{-8}$ & 7 & $20 \pm 7^{a}$ \\
$1 \times 10^{-6}$ & 17 & $337 \pm 29$ \\
$1 \times 10^{-4}$ & 6 & $451 \pm 105$ \\
\hline
\end{tabular}

${ }^{a}$ The values represent the mean \pm SEM.

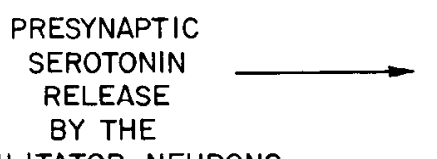

FACILITATOR NEURONS

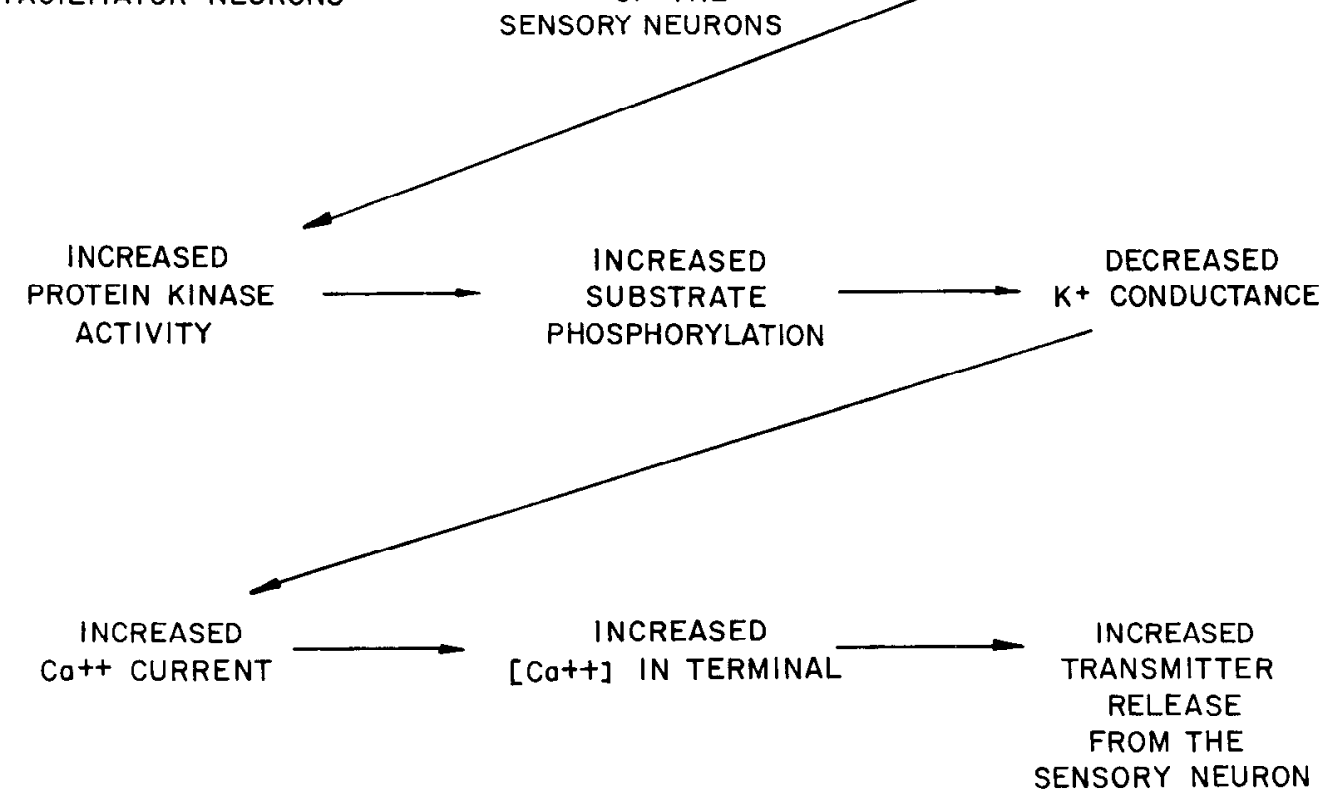

Figure 1. Sequence of events thought to be involved in the sensitization of the gill withdrawal reflex in Aplysia. 

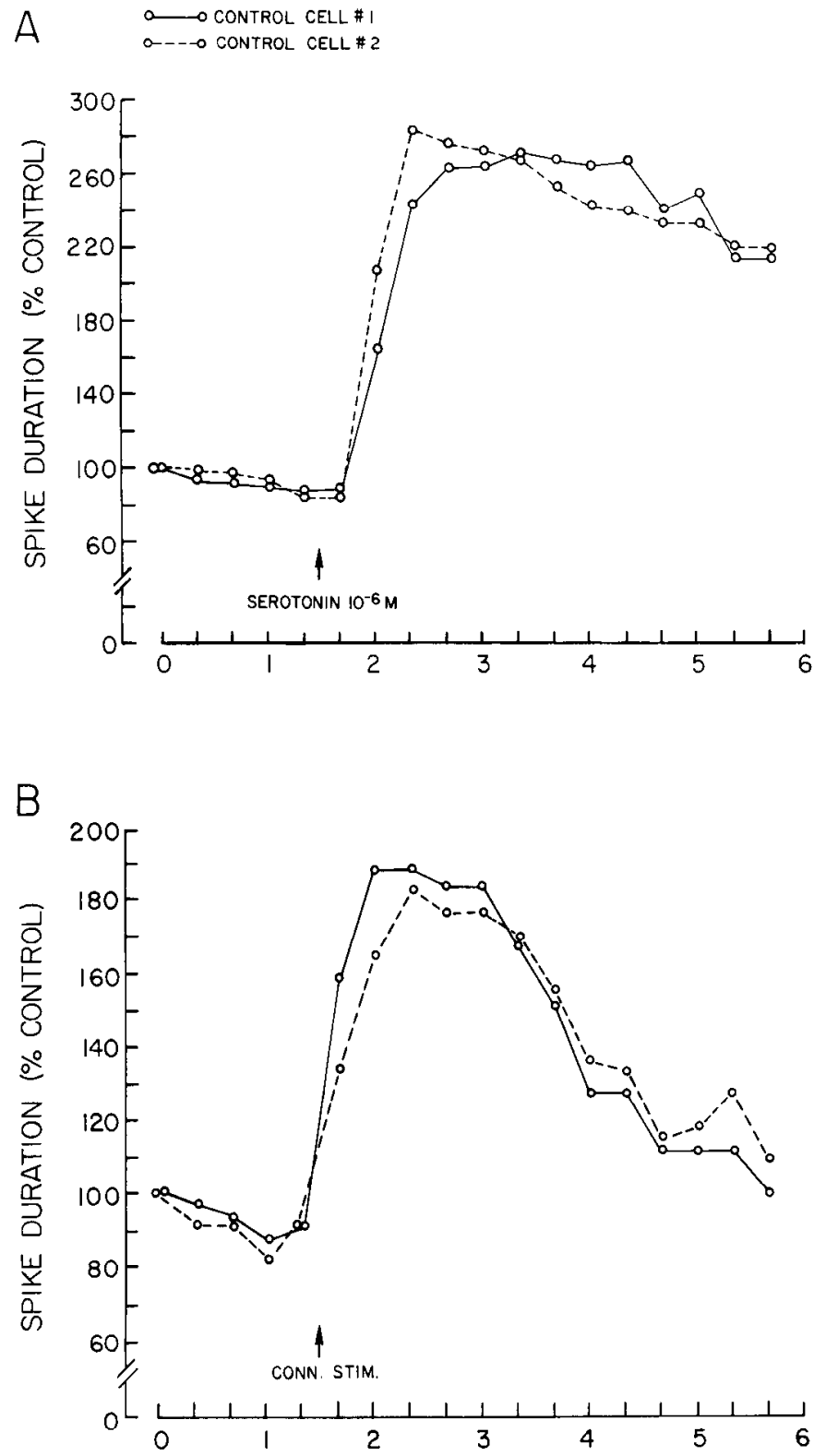

MINUTES

Figure 2. Parallel increase of spike duration from pairs of sensory neurons within the same ganglion. $A$, Effect of serotonin. Intracellular recordings were obtained from two sensory neurons (LE cells). After a brief rest period, 5-msec depolarization pulses were applied to each neuron every $10 \mathrm{sec}$. After $1.5 \mathrm{~min}$, a concentrated solution of serotonin was applied to the 5 -ml bath solution containing the ganglion in order to bring the final concentration to $10^{-6}$ M. $B$, Effect of facilitator neurons. The experimental protocol was similar to the one described in $A$ except that the left connective nerve tract was stimulated electrically (five 1 -sec trains of pulses, $7 \mathrm{~Hz}$, every $2 \mathrm{sec}$ ) to activate the facilitator neurons. In $A$ and $B$, the values are normalized to the initial spike duration. Artificial sea water contained $50 \mathrm{~mm}$ TEA. Each data point, is the average duration of two consecutive spikes.

erably or blocked completely by injection of the kinase inhibitor (Fig. 3). The average effect of serotonin in the cells injected with the inhibitor was only $23 \pm 8 \%$ of that observed in the control cells. Thus, $77 \%$ of the effect of serotonin was prevented by the kinase inhibitor.
In contrast, in three paired comparisons in which the vehicle buffer (see "Materials and Methods") was injected into the experimental neuron, the injected cells responded to serotonin as effectively as the uninjected cells. The ratio of spike broadening was $103 \pm 2$.

Protein kinase inhibitor blocks the spike broadening and synaptic facilitation produced by the activity of facilitator cells. Because the inhibitor blocked spike broadening when serotonin, the presumed facilitating transmitter, was applied exogenously, we were encouraged to determine whether it also would block spike broadening when the endogenous transmitter was released by stimulation of the left connective which excites the facilitating interneurons (Hawkins et al., 1981b). In each of four experiments, injection of the kinase inhibitor reduced or blocked completely the spike broadening evoked by synaptic stimulation (Fig. 4). The average decrease produced by the inhibitor was $80 \pm 12 \%$.

The ability of the kinase inhibitor to block spike broadening suggests that the facilitation of the synaptic actions evoked by a sensory cell should be blocked also. To carry out these experiments, we impaled two sensory neurons and a common follower cell and monitored the excitatory synaptic actions produced by each of the sensory neurons. In two experiments, we injected one sensory cell with the kinase inhibitor and used the other to monitor the facilitating effect. The uninjected sensory cell showed spike broadening and facilitation of its EPSP. In contrast, spike broadening was greatly reduced in the injected cell and its evoked EPSP was only slightly facilitated (Fig. 5 ). This facilitation lasted only briefly and then was followed by the depression characteristic of repeated stimulation (see, for example, Fig. 4 and pre-serotonin controls in Figs. 2 and 3).

Memory for short term sensitization is determined by events that occur before the step of phosphorylation of the substrate protein. Facilitation appears to involve phosphorylation of a protein that results in blockade of a $\mathrm{K}^{+}$channel. One of several steps outlined in Figure 1 could account for the persistence of the phosphorylated state. Which of these steps is the determining one? Since the protein kinase inhibitor inactivates the catalytic subunit of the cAMP-dependent protein kinase, the inhibitor can be used to determine whether the time course of short term memory depends on a persistently active protein kinase.

Two possible schemes are considered in Figure 6. If the persistence of the memory (duration during which the spike remains broadened and transmitter release remains enhanced) depends upon stable phosphorylation of the substrate protein, then, once the protein has been phosphorylated, injecting the kinase inhibitor should not affect the rate of which the memory decays (Fig. 6A). Alternatively, if phosphorylation and dephosphorylation occur rapidly, then the memory must reside in the persistent activity of the kinase. Therefore, injection of the kinase inhibitor should abolish the memory rapidly (Fig. $6 B$ ).

To examine this question, we recorded from two sensory cells in each of three experiments, allowing them both to respond fully to serotonin; we then injected one cell with the inhibitor and compared the rate of decay of the broadening in the control and injected cells. Injection 

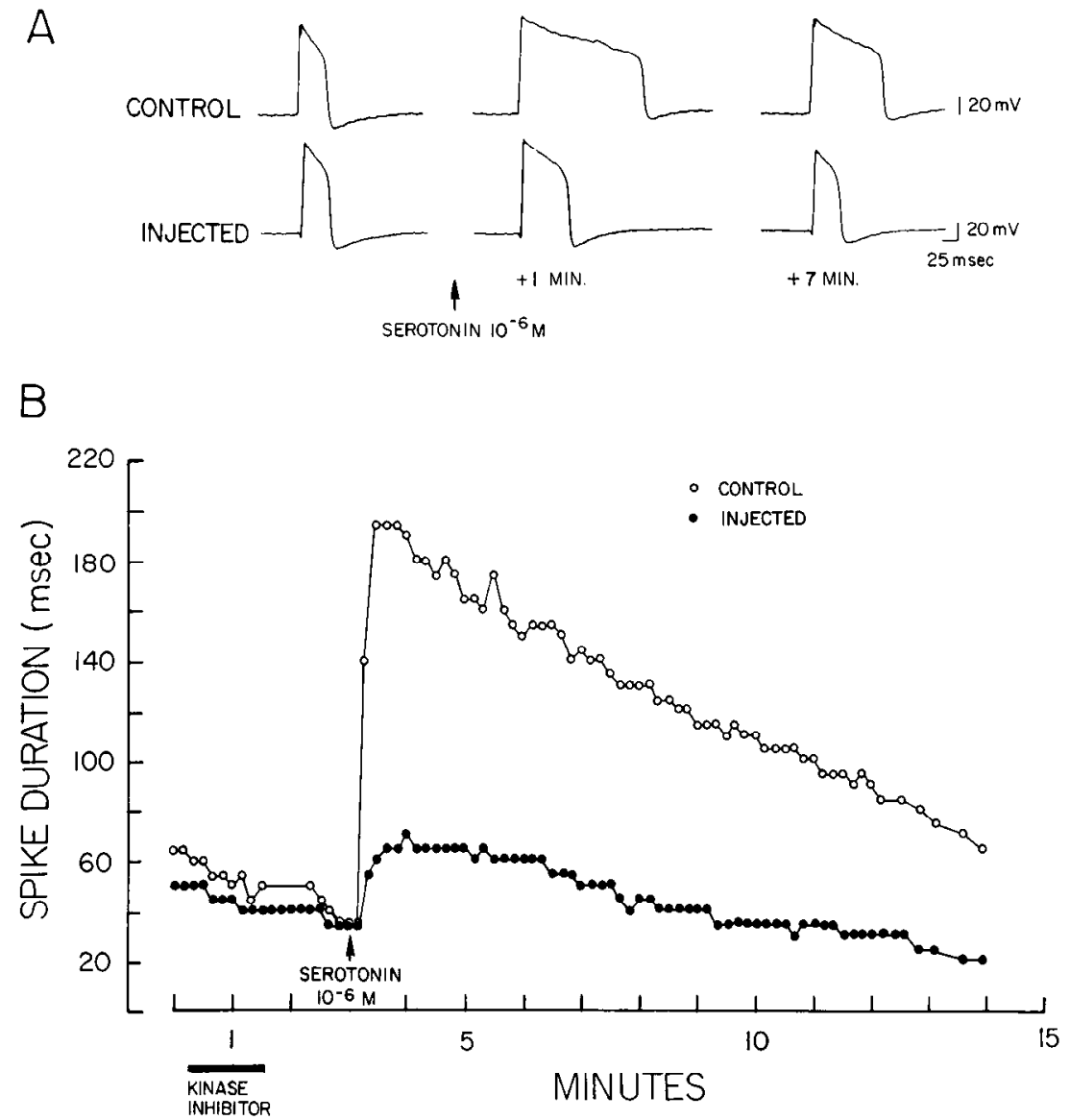

Figure 3. Spike broadening in response to serotonin is prevented by prior injection of the protein kinase inhibitor. $A$, Sample records from control and injected cells; $B$, quantitation of the effect of the kinase inhibitor on the serotonin-induced broadening of the spike duration illustrated in $A$. Action potentials were recorded from a pair of sensory neurons simultaneously. Each cell was stimulated intracellularly every $10 \mathrm{sec}$. The experimental cell was injected with the inhibitor. At the arrow, $10^{-1 i} \mathrm{M}$ serotonin was applied to the bath. The bar indicates the time for injecting the inhibitor intracellularly.

of the inhibitor clearly shortened the effect of serotonin (Fig. 7). These results suggest that short term memory results in persistent kinase activity dependent upon a persistent elevation in cAMP. Cedar and Schwartz (1972) have shown that brief exposure to serotonin can elevate the amount of newly synthesized cAMP in the abdominal ganglion for more than $20 \mathrm{~min}$. In the accompanying paper, Bernier et al. (1982) show a similar increase in single sensory cells. In view of these results, we favor the idea that the memory resides in the sustained elevation of the cAMP.

Injection of protein kinase inhibitor does not accelerate the decrease in spike duration that accompanies habituation. Eliciting the gill withdrawal reflex repeatedly leads to habituation of the reflex (Pinsker et al., 1970). This is caused by the depression of the transmitter release at the terminals that the sensory neurons which innervate the siphon skin make on gill motor neurons (Castellucci and Kandel, 1974). Inactivation of $\mathrm{Ca}^{2+}$ current in the sensory neurons underlies synaptic depression: in the presence of TEA, this is manifested as a decrease in the duration of the action potential during repeated stimulation (Klein et al., 1980). Although there is no evidence to support the idea, it is conceivable that habituation is a negative image of the process of sensitization, involving a progressive decrease in cAMP in the sensory neuron and therefore a progressive decrease in the activity of the protein kinase (see Simmons, 1982). If so, injection of the kinase inhibitor should enhance the neural mechanism underlying habituation and accelerate the shortening of the action potential.

We therefore compared the rates at which spikes shorten in TEA in control and injected sensory neurons from the same ganglion. We found that the rate of spike shortening was similar in the two cells (Fig. 8). 'T'o improve the signal-to-noise ratio, we also have analyzed a group of experiments in which the initial spike duration was longer than $200 \mathrm{msec}$; these cells also showed no difference. Our results show that habituation does not involve cAMP-dependent protein phosphorylation and support the earlier conclusion derived from voltage clamp analyses which indicate that habituation and sensitization involve two different mechanisms (Klein et al., 1980). The spike shortening in TEA that accompanies habituation results from inactivation of the $\mathrm{Ca}^{2+}$ channel; the spike broadening that underlies sensitization is due to a closure of a K${ }^{+}$channel which acts on the $\mathrm{Ca}^{2+}$ current only indirectly.

\section{Discussion}

Direct evidence for a role of $c A M P$-dependent protein phosphorylation in presynaptic facilitation underlying 


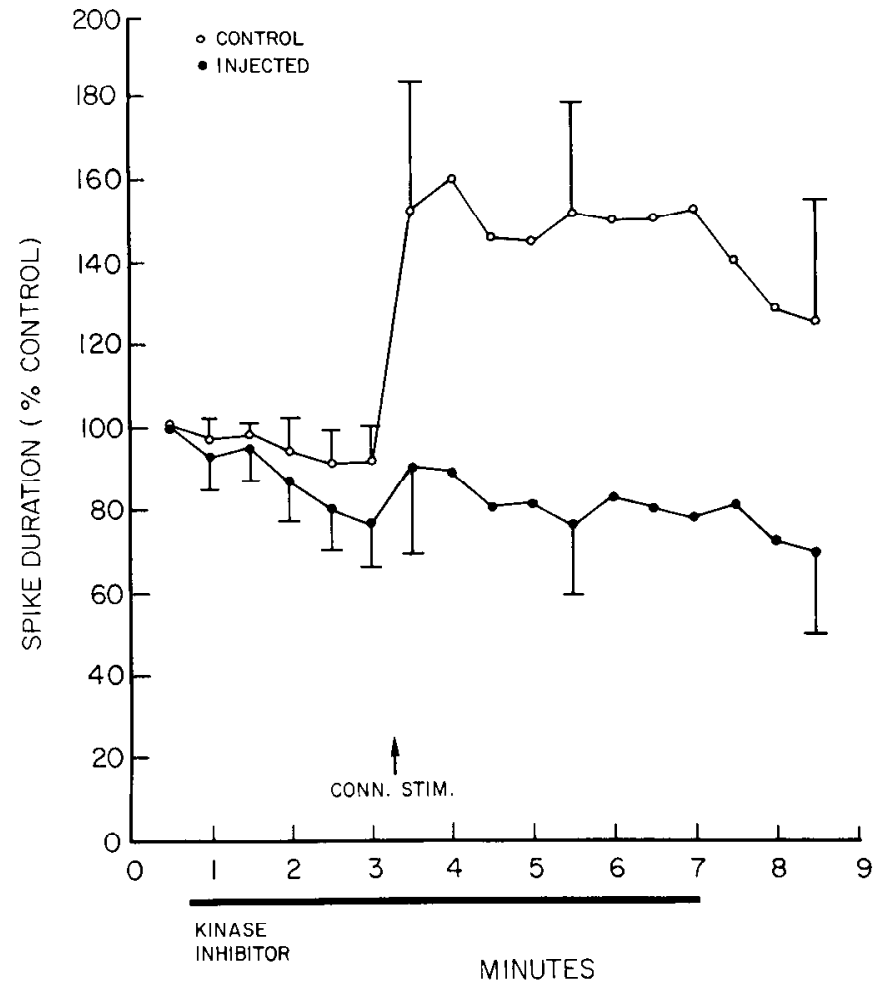

Figure 4. Spike broadening in response to stimulation of the left connective is prevented by injection of the protein kinase inhibitor. Action potentials were recorded from pairs of sensory neurons simultaneously. Each cell was stimulated intracellularly every $10 \mathrm{sec}$. The experimental cells were injected with the inhibitor (bar, time to inject). Then the left connective tract was stimulated electrically to produce spike broadening. Each data point is the mean \pm SEM of four cells. Only representative error bars are illustrated.

sensitization. It seems likely that most, and possibly all, of the actions of cAMP in eukaryotic cells are mediated by protein phosphorylation (Greengard, 1978). In this and in an earlier paper (Castellucci et al., 1980), we have provided direct evidence that cAMP-dependent protein phosphorylation is responsible for the depression of a $\mathrm{K}^{+}$ channel, the broadening of the action potential, and the increased $\mathrm{Ca}^{2+}$ influx which underlie the presynaptic facilitation responsible for short term sensitization. This conclusion is based on the following evidence. Direct activation of the facilitator neurons, or application of serotonin, the putative transmitter released by these neurons, increases cAMP in the sensory neuron of the gill withdrawal reflex (Bernier et al., 1982). Activation of the facilitator neurons, application of serotonin, or intracellular injection of cAMP all enhance transmitter release (Brunelli et al., 1976; Hawkins et al., 1981b). These conditions also block a specific $\mathrm{K}^{+}$channel that contributes importantly to the repolarization of the action potential (Klein et al., 1982; Siegelbaum et al., 1982). The broadening of the action potential allows more $\mathrm{Ca}^{2+}$ to flow into the terminals and accounts for the enhanced release of transmitter (Klein and Kandel, 1978, 1980; Camardo et al., 1981). The increase in input resistance, probably resulting from a reduction of $\mathrm{K}^{+}$current, the broadening of the action potential, and the enhanced transmitter release can be produced by injection of the catalytic subunit of cAMP-dependent protein kinase into the presynaptic neuron (Castellucci et al., 1980). As we have shown here, these several actions all are blocked by the specific inhibitor of the protein kinase.

Recent experiments from several laboratories suggest that cAMP-dependent protein phosphorylation may prove to be a general mechanism for modulating $\mathrm{K}^{+}$ channels in molluscan neurons. In the gill withdrawal reflex, cAMP-dependent phosphorylation leads to a depression of a novel serotonin-modulated $\mathrm{K}^{+}$channel (the S channel; Klein and Kandel, 1978, 1980; Klein et al., 1982; Siegelbaum et al., 1982). In certain neurons of the

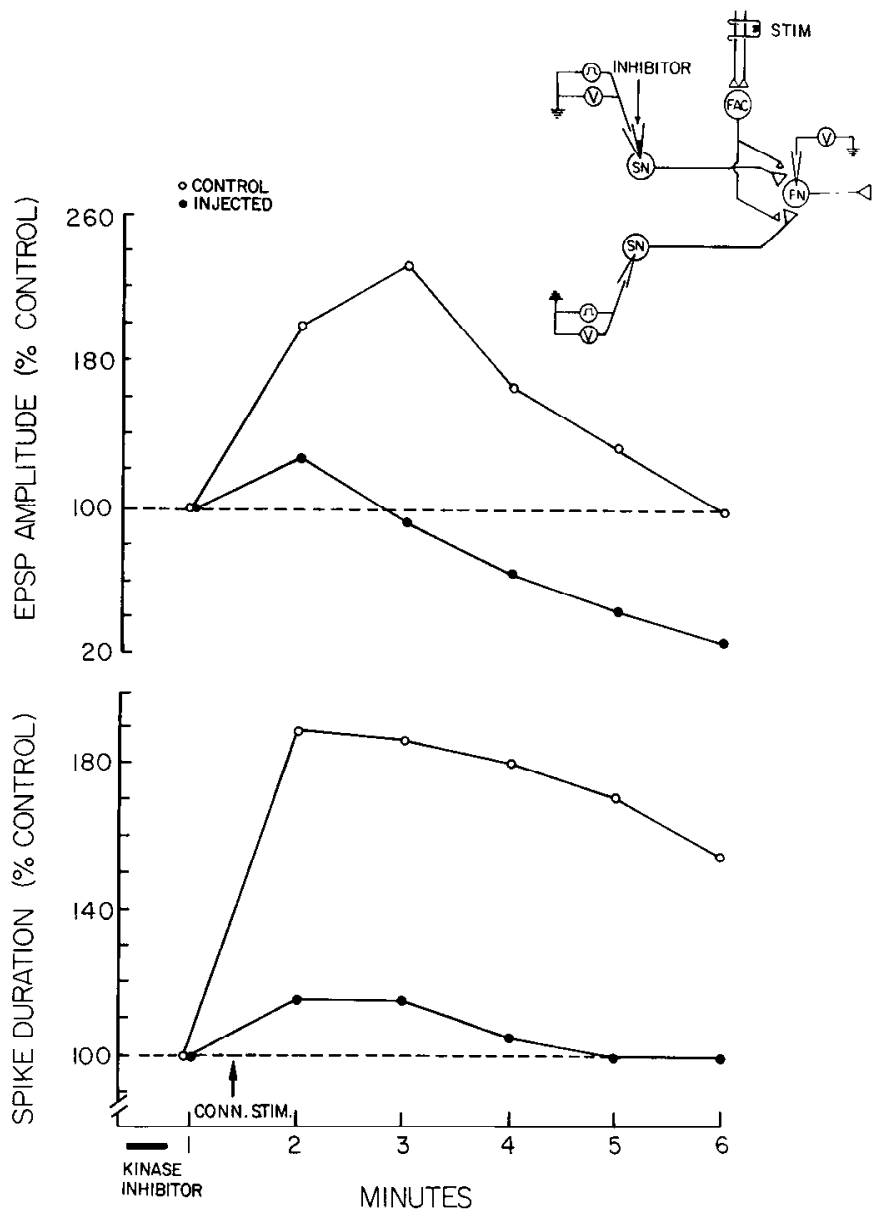

Figure 5. Spike broadening and EPSP facilitation are blocked by injection of the kinase inhibitor. Action potentials were recorded from a pair of sensory neurons simultaneously and their evoked EPSPs were recorded in a common follower cell every $10 \mathrm{sec}$ (see inset). One sensory cell was used as control; the other sensory cell was injected with the kinase inhibitor. The spike duration of the control cell and its evoked EPSP are compared to the spike duration and the evoked EPSP of the injected cell. The connective nerve tract was stimulated electrically (one 10 -sec train, $8-\mathrm{Hz}$ pulses) to produce spike broadening and EPSP facilitation. The injection (bar) was completed before the connective was simulated (arrow). Spike durations and EPSP amplitudes were normalized to the values recorded before stimulation of the left connective. The concentration of $\mathrm{Ca}^{2+}$ was $25 \mathrm{~mm}$ and that of $\mathrm{Mg}^{2+}$ was $100 \mathrm{~mm}$ to reduce background synaptic activity; the TEA concentration was 50 mM. Each data point is the mean of six samples. The abbreviations used in the inset are: $F A C$, facilitator cell; $F N$, follower neuron; $S N$, sensory neuron; $S T I M$, stimulation; $V$, voltage. 
A

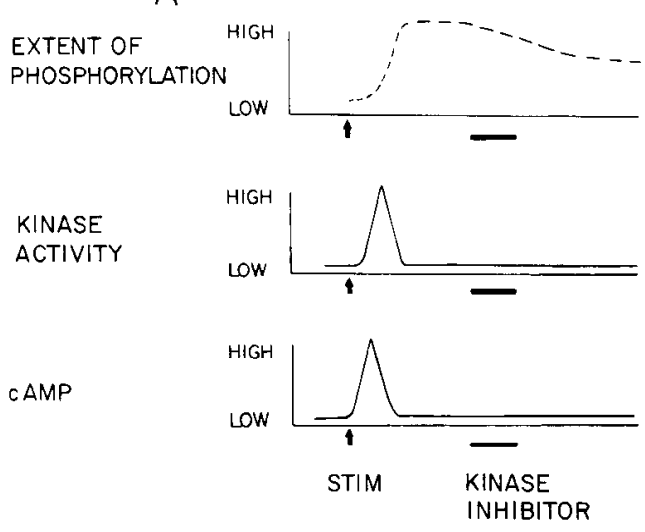

B
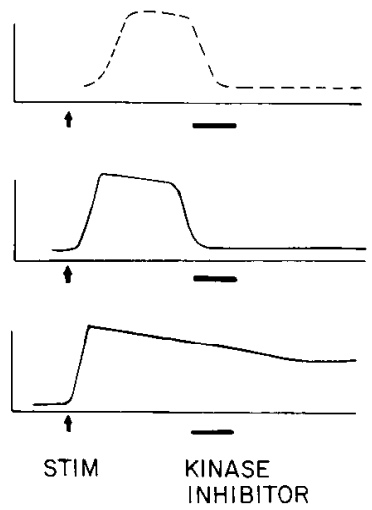

TIME $\rightarrow$

Figure 6. Schematic diagram illustrating two possible sites for the short term memory of sensitization. It is assumed that increased spike duration and increased transmitter released are related to the degree of phosphorylation of a protein related to a $\mathrm{K}^{+}$channel. In the scheme illustrated in $A$, injection of the inhibitor will not change the rate at which the memory decays; in contrast, the rate of decay will be accelerated in the scheme illustrated in $B$. STIM, activation of the facilitator neurons or presence of serotonin; bar, injection of the kinase inhibitor. (See the text for details.)

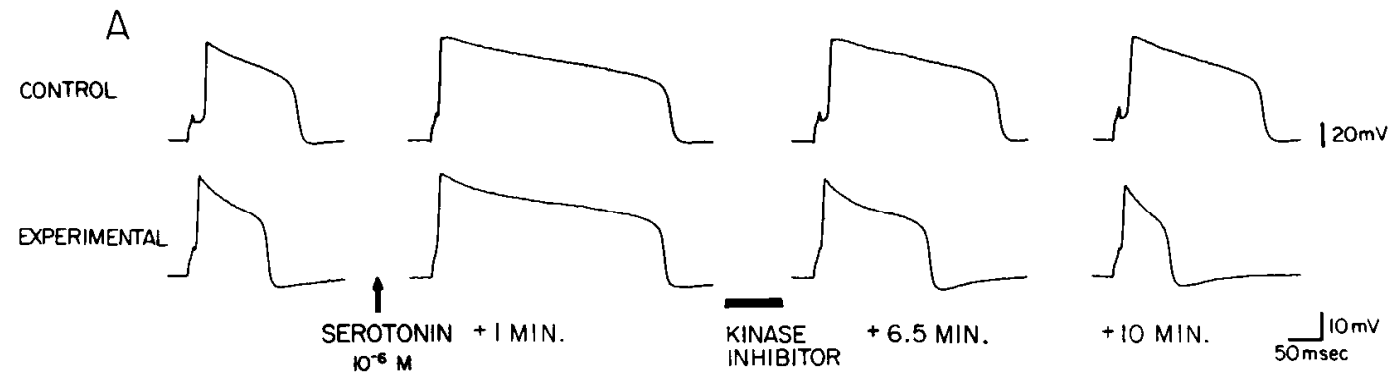

B

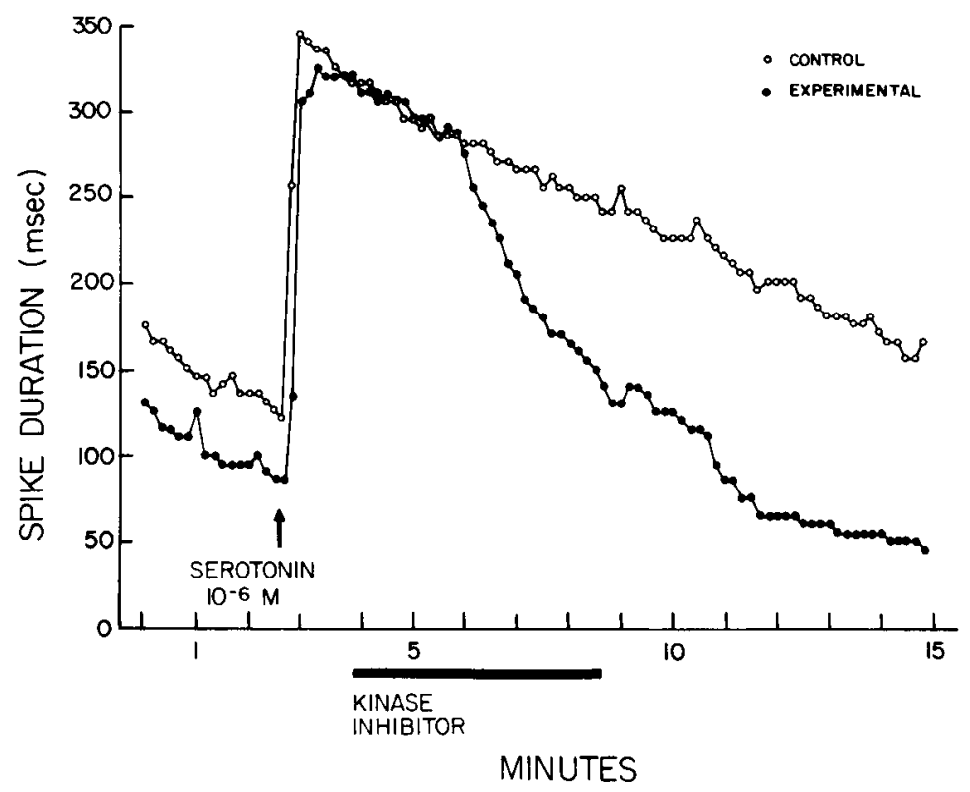

Figure 7. Injection of the kinase inhibitor reverses the action of serotonin. In order to test the schemes illustrated in Figure 6 , action potentials were recorded every $10 \mathrm{sec}$ from a pair of sensory neurons simultaneously and allowed to respond to serotonin. One cell of the pair was injected with the inhibitor; injection is indicated by the bar. The effect decayed more rapidly in the injected cell. $A$, Sample recordings before serotonin, at the peak of the serotonin effect, and after the inhibitor injection. $B$, Quantitation of the effect of the kinase inhibitor illustrated in part $A$. 


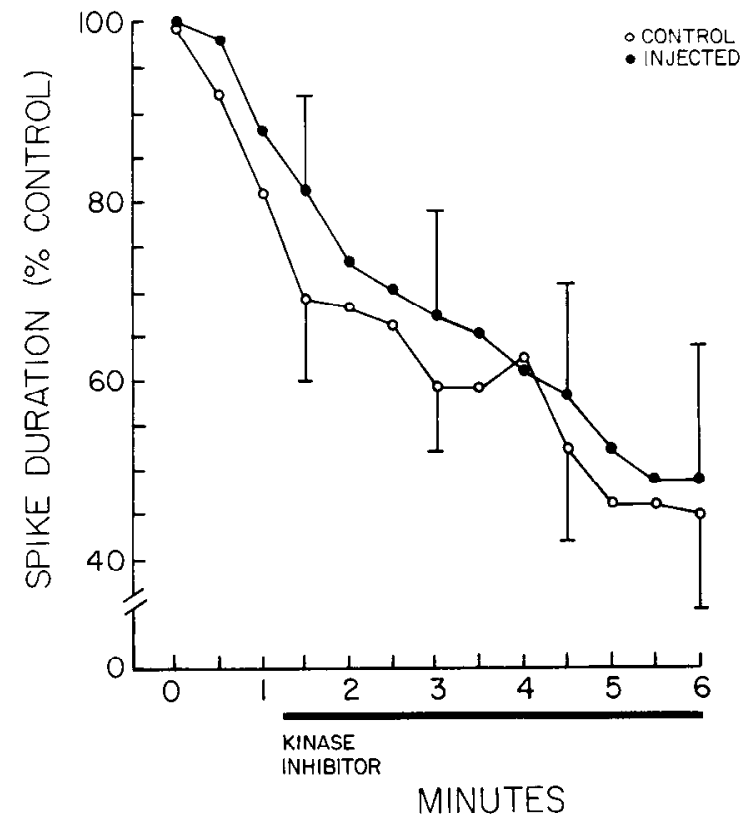

Figure 8 . Injection of the kinase inhibitor does not affect the rate of shortening of spike duration underlying reflex habituation. This is a summary of four experiments in which pairs of sensory cells were recorded every $10 \mathrm{sec}$ simultaneously. One member of the pair was injected with the inhibitor. Injection is indicated by the bar. The $100 \%$ control values were $85 \mathrm{mV}$ and $150 \mathrm{msec}$ for the experimental cells and $88 \mathrm{mV}$ and $144 \mathrm{msec}$ for the control cells. Error bars, \pm SEM.

land snail, Helix, a $\mathrm{K}^{+}$channel with similar properties also is depressed by serotonin or cAMP (Deterre et al., 1981). In the bag cells of Aplysia, cAMP-dependent phosphorylation decreases a $\mathrm{K}^{+}$current that is activated by $\mathrm{Ca}^{2+}$ (Kaczmarek et al., 1980; Kaczmarek and Strumwasser, 1981). In cell R15 of Aplysia, a K' conductance is increased in response to serotonin (Drummond et al., 1980; Lemos et al., 1981). Finally, in the photoreceptor neurons of Hermissenda, $\mathrm{K}^{+}$channels seem to be depressed by a cAMP-dependent mechanism (Acosta-Urquidi et al., 1981; Alkon, 1979). Since $\mathrm{K}^{+}$channels determine the duration of the action potential in neurons, their modulation can have important consequences for increasing of decreasing $\mathrm{Ca}^{2+}$ influx and transmitter release. This mechanism, now demonstrated in a variety of invertebrates, is also likely to occur in vertebrate cells.

The molecular mechanism for the memory for synaptic facilitation resides in a step prior to the phosphorylation of the substrate protein. By injecting the kinase inhibitor after the spike was broadened, we found that the spike shortened rapidly; this result shows that short term sensitization depends on an active kinase. Camardo and Kandel (J. S. Camardo and E. R. Kandel, manuscript in preparation) recently have compared the time course of the $\mathrm{K}^{+}$channel depression produced by injecting cAMP intracellularly, which circumvents the steps prior to the cyclase, and by bath application of serotonin, which activates the cyclase. cAMP produced a transient depression that outlasted the injection only briefly, indicating that the kinase is active only as long as cAMP is elevated and suggesting that regulatory subunits rapidly reassociate with the catalytic subunits in the absence of cAMP. In contrast, serotonin, which stimulates the cyclase, produces prolonged activation. In addition, in the companion paper, Bernier et al. (1982) show that cAMP remains elevated for several minutes after stimulation of individual sensory neurons. Thus, it appears that facilitation resides not in the persistent activity of the kinase but in the elevated concentration of cAMP. Persistent elevation in cAMP could result from either a persistent depression of phosphodiesterase or a persistent activation of adenylate cyclase.

Habituation and sensitization use independent molecular mechanisms. Consistent with voltage clamp analyses of the sensory neurons which indicate that different mechanisms cause synaptic depression and synaptic facilitation, we have shown that the synaptic depression underlying habituation does not depend on cAMP. Habituation appears to be caused by a direct modification of the $\mathrm{Ca}^{2+}$ channel. In contrast, sensitization is the result of a decrease in $\mathrm{K}^{+}$conductance, which affects the $\mathrm{Ca}^{2+}$ channel indirectly (Klein et al., 1980).

The present studies of facilitation deal only with short term sensitization which lasts less than $1 \mathrm{hr}$, but with repeated training, sensitization can be prolonged for days or weeks (Pinsker et al., 1973). It will be important to determine whether the long term memory of sensitization also involves serotonin, cAMP, and protein phosphorylation or whether other mechanisms are necessary for the conversion of the short to the long term form of memory.

\section{References}

Acosta-Urquidi, J., D. L. Alkon, J. Olds, J. T. Neary, E. Zebley, and G. Kuzma (1981) Intracellular protein kinase injection stimulates biophysical effects of associative learning in $\mathrm{Her}$ missenda photoreceptors. Soc. Neurosci. Abstr. 7: 944.

Alkon, D. (1979) Voltage-dependent calcium and potassium ion conductances: A contingency mechanism for an associative learning model. Science 205: 810-816.

Bernier, L., V. F. Castellucci, E. R. Kandel, and J. H. Schwartz (1982) Facilitatory transmitter causes a selective and prolonged increase in adenosine $3^{\prime}: 5^{\prime}$-monophosphate in sensory neurons mediating the gill and siphon withdrawal reflex in Aplysia. J. Neurosci. 2: 1682-1691.

Brunelli, M., V. F. Castellucci, and E. R. Kandel (1976) Synaptic facilitation and behavioral sensitization in Aplysia: Possible role of serotonin and cyclic AMP. Science 194: 1178-1181.

Byrne, J., V. F. Castellucci, and E. R. Kandel (1974) Receptive fields and response properties of mechanoreceptor neurons innervating siphon skin and mantle shelf in Aplysia. J. Neurophysiol. 37: 1041-1064.

Camardo, J. S., M. Klein, and E. R. Kandel (1981) Sensitization in Aplysia: Serotonin elicits a decrease in sensory neuron $\mathrm{K}^{+}$ current not related to $I_{K}$ early or $I_{K} \mathrm{Ca}^{++}$. Soc. Neurosci. Abstr. 7: 836.

Castellucci, V. F., and E. R. Kandel (1974) A quantal analysis of the synaptic depression underlying habituation of the gillwithdrawal reflex in Aplysia. Proc. Natl. Acad. Sci. U. S. A. 71: 5004-5008.

Castellucci, V. F., E. R. Kandel, J. H. Schwartz, F. D. Wilson, A. C. Nairn, and P. Greengard (1980) Intracellular injection of the catalytic subunit of cyclic AMP-dependent protein kinase simulates facilitation of transmitter release underlying behavioral sensitization in Aplysia. Proc. Natl. Acad. Sci. U. S. A. 77: 7492-7496.

Castellucci, V. F., J. H. Schwartz, E. R. Kandel, A. Nairn, and 
P. Greengard (1981) Protein inhibitor of the cyclic AMPdependent protein kinase can block the onset of, as well as reverse the electrophysiological correlates of sensitization of the gill-withdrawal reflex in Aplysia. Soc. Neurosci. Abstr. 7: 836.

Cedar, H., and J. H. Schwartz (1972) Cyclic adenosine monophosphate in the nervous system of Aplysia californica. II Effect of serotonin and dopamine. J. Gen. Physiol. 60: 570587.

Deterre, P., D. Paupardin-Tritsch, J. Bockaert, and H. M. Gerschenfeld (1981) Role of cyclic AMP in a serotoninevoked slow inward current in snail neurons. Nature 290 : 783-785.

Drummond, A. H., J. A. Benson, and I. B. Levitan (1980) Serotonin-induced hyperpolarization of an identified Aplysia neuron is mediated by cyclic AMP. Proc. Natl. Acad. Sci. U. S. A. 77: 5013-5017.

Eisenstadt, M., J. E. Goldman, E. R. Kandel, H. Koike, J. Koester, and J. H. Schwartz (1973) Intrasomatic injection of radioactive precursors for studying transmitter synthesis in identified neurons of Aplysia californica. Proc. Natl. Acad. Sci. U. S. A. 70: 3371-3375.

Greengard, P. (1978) Cyclic Nucleotides, Phosphorylated Proteins and Neuronal Function, Raven Press, New York

Hawkins, R. D., C. H. Bailey, M. Chen, and E. R. Kandel (1981a) Cellular studies of identified neurons producing presynaptic facilitation in Aplysia. In Advances in Physiological Sciences-Proceedings and Satellite Symposia of the 28th International Congress of Physiological Sciences, Vol. 20, pp. 287-392, Pergamon Press, Elmsford, NY.

Hawkins, R. D., V. F. Castellucci, and E. R. Kandel (1981b) Interneurons involved in mediation and modulation of gillwithdrawal reflex in Aplysia. II. Identified neurons produce heterosynaptic facilitation contributing to behavioral sensitization. J. Neurophysiol. 45: 315-326.

Kaczmarek, L. K., and F. Strumwasser (1981) Net outward currents on bag cell neurons are diminished by a cAMP analogue. Soc. Neurosci. Abstr. 7: 932.

Kaczmarek, K., K. R. Jennings, F. Strumwasser, A. C. Nairn, U. Walter, F. O. Wilson, and P. Greengard (1980) Microinjection of catalytic subunit of cyclic AMP-dependent protein kinase cnhances calcium action potentials of bag cell neurons in cell culture. Proc. Natl. Acad. Sci. U. S. A. 77: 7487-7491.

Klein, M., and E. R. Kandel (1978) Presynaptic modulation of voltage-dependent $\mathrm{Ca}^{2+}$ current: Mechanism for behavioral sensitization in Aplysia californica. Proc. Natl. Acad. Sci. U. S. A. 75: 3512-3516.

Klein, M., and E. R. Kandel (1980) Mechanism of calcium current modulation underlying presynaptic facilitasion and behavioral sensitization in Aplysia. Proc. Natl. Acad. Sci. U. S. A. 77: 6912-6916.

Klein, M., E. Shapiro, and E. R. Kandel (1980) Synaptic plasticity and the modulation of the $\mathrm{Ca}^{2+}$ current. J. Exp. Biol. 89: 117-157.

Klein, M., J. Camardo, and E. R. Kandel (1982) Serotonin modulates a new potassium current in the sensory neurons that show presynaptic facilitation in Aplysia. Proc. Natl. Acad. Sci. U. S. A., 79: 5713-5717.

Krebs, E. G., and J. A. Beavo (1979) Phosphorylation-dephosphorylation of enzymes. Annu. Rev. Biochem. 48: 929-959.

Lemos, J., I. Novak-Hofer, and I. B. Levitan (1981) Serotonin effects on protein phosphorylation within a single living nerve cell. Soc. Neurosci. Abstr. 7: 932.

McPherson, J. M., S. Whitehouse, and D. A. Walsh (1979) Possibility of shape conformers of the protein inhibitor of the cyclic adenosine monophosphate dependent protein kinase. Biochemistry 18: $4835-4844$.

Nimmo, G. A., and P. Cohen (1978) Purification and characterization of protein phosphatase inhibitor-1 from rabbit skeletal muscle. Eur. J. Biochem. 87: 341-351.

Pinsker, H., I. Kupfermann, V. Castellucci, and E. R. Kandel (1970) Habituation and dishabituation of the gill-withdrawal reflex in Aplysia. Science 167: 1740-1742.

Pinsker, H. M., W. A. Hening, T. J. Carew, and E. R. Kandel (1973) Long-term sensitization of a defensive withdrawal reflex in Aplysia. Science 182: 1039-1042.

Rall, T. W. (1979) General regulatory role of cyclic nucleotides in hormone and neurohormone action. In The Neurosciences: Fourth Study Program, pp. 859-872, MIT Press, Cambridge, MA.

Rosen, O. M., and E. G. Krebs, eds. (1981) Protein Phosphorylation: Cold Spring Harbor Conferences on Cell Proliferation, Vol, 8, Cold Spring Harbor Laboratory, Cold Spring Harbor, NY.

Sicgelbaum, S., J. S. Camardo, and E. R. Kandel (1982) Serotonin and cAMP close single $\mathrm{K}^{+}$channels in Aplysia sensory neurons. Nature, 299:413-417.

Simmons, L. K. (1982) 'Theophylline modulates synaptic efficacy and short-term plasticity in the rat in vitro dentate gyrus. Doctoral thesis, Harvard University, Boston, MA.

Tomosky-Sykes, T. K. (1978) Pharmacology of presynaptic facilitation of the gill-withdrawal reflex in Aplysia. Soc. Neurosci. Abstr. 4: 208

Walsh, D. A., J. P. Perkins, and E. G. Krebs (1968) An adenosine $3^{\prime}, 5^{\prime}$-monophosphate-dependent protein kinase from rabbit skeletal muscle. J. Biol. Chem. 243: 3763-3765. 